\title{
Synergetic Model of Electro-friction Interaction
}

\author{
Igor Plokhov \\ Department of Electric Drive and Auto- \\ mation Systems \\ Pskov State University \\ Pskov, Russia \\ igor_plohov@list.ru \\ Igor Savraev \\ Department of Electric Drive and Auto- \\ mation Systems \\ Pskov State University \\ Pskov, Russia \\ igor_savraev@mail.ru
}

\author{
lexander Ilyin \\ Department of Electric Drive and Auto- \\ mation Systems \\ Pskov State University \\ Pskov, Russia \\ al.ilyin@yandex.ru \\ Nikita Kotkov \\ Department of Electric Drive and Auto- \\ mation Systems \\ Pskov State University \\ Pskov, Russia \\ 4ce@goodgame.ru
}

\author{
Oksana Kozyreva \\ Department of Electric Drive and Auto- \\ mation Systems \\ Pskov State University \\ Pskov, Russia \\ ks_33n@mail.ru
}

\begin{abstract}
The paper describes algorithms and structure of the electro-friction interaction synergetic model. The results of theoretical modelling and experimental study of sliding electrical contact are given. The comparison of theoretical and experimental results made in the paper proves high validity of the model and its programmatic implementation.
\end{abstract}

Keywords-fractal theory, simulation modelling, sliding contact, synergetic.

\section{INTRODUCTION}

The basic approaches to the modern explanation of the physical processes in the sliding electrical contact are the next.

A common surface of two contacting rough bodies divides into many separate spots. When the flow of energy gets through the surface, it overcomes additional constriction resistance because of the nonuniform flow lines. In addition, there is the resistance of the surface films.

The theory of the electro-frictional interaction (EFI) at the time is at a critical time when there are large bulk of experimental data, hypotheses and different models, which could not be adequate to the studied processes. To overcome this conflict the new physical views and presentations must be involved in the applied area.

At present it is developing synergetics, the theory of self-organizing systems, and fractal theory studying selfsimilar evolutionary structures that cannot be described within Euclidian geometry.

Synergetics is studying the processes of the selforganizing, stability and disintegration of different nature structures forming in the open systems and the ordered state of which is connected to cooperative behaviour of theirs subsystems. This leads to the forming of selforganizing structures as the result of energy and material exchange with the environment when equilibrium has established of the entropy production and reduction [1] -

[5]. The evolution of a system is considered as transition through the series of thermodynamic quasi-equilibrium states [6]. Fractal theory [7] - [10] has become the base for quantitative description of the self-organizing structures using the fractal dimension as a parameter.

\section{Model Of Sliding Contact Transient Layer}

The transient layer of sliding electric contact (SC) is representable as set of the contact elements (CE) placed in nodes of a regular grid on the transitional plane (TP). We will describe each CE with the state vector having components.

Components of the power vector $F$ are independent input influences: pressure force $F_{p}$, velocity of relative movement in contact couple of $v$, external voltage applied to contact $U$ , environment temperature $\theta_{e n v}$, vector of concentration of environment chemical reagents $Z$.

We will divide all components of the state vector of a contact element into the following classes. Mechanical $V_{M}$ : contact stiffness $S_{C}$; contact damping $K_{C}$; contact approach $Y_{C}$; contact force $F_{C}$; microhardness $q$; density $\rho$; coefficient of boundary friction $k_{f r}$. Electrical $V_{E}$ : voltage $U$ (it is identical for all contact elements); fritting voltage $U_{f}$; electric conductance $g_{E}$ or resistance $\rho_{E}$; contact capacity $C_{E}$; current $I$ through $C_{E}$. Thermal $V_{T}$ : heat capacity $C_{\theta}$; heat conductivity $k$; melting temperature $\theta_{m}$; evaporation temperature $\theta_{e v}$; CE temperature $\theta$. Chemical $V_{H}$ : vector of chemical composition $\hbar$; intensity of the main chemical reactions of $V_{\hbar}$.

Let's determine the state vector by the sum of this four components

$$
\mathrm{V}=\mathrm{V}_{\mathrm{M}}+\mathrm{V}_{\mathrm{E}}+\mathrm{V}_{\theta}+\mathrm{V}_{\mathrm{H}}
$$

Voltage $U$ is identical for all $\mathrm{CE}$, however the value of current will be different for the different types and characteristics of conductivity, different temperatures, approaches, and etc. Besides, the flow of current leads to emitting power in $\mathrm{CE}$ and increases temperature $\theta$, 
which significantly affects conductivity of the element and conductivity of the neighbor areas.

In each CE there are substances and compounds of different concentration which can react with each other and with the materials of contact bodies. Either they can be passive or be catalysts and inhibitors for other reactions.

\section{Modification Of the State Vector Components}

The operations described below provide a basis for the dynamic processes in $\mathrm{CE}$ and contain the main computational procedures.

In the transient layer matrix we allocate clusters of direct and film conductivity ( $\alpha$-clusters and $\beta$-clusters). For this we use an allocation procedure that translates the elements of each cluster into an additional matrix.

After calculating the number of elements that make up the cluster $N_{i}$ we calculate the characteristic radius of the cluster $r_{c l}$ as the gyration radius $R_{g}$ :

$$
\begin{gathered}
R_{q}=\sqrt{\frac{1}{N} \sum_{i=1}^{N} r_{i}^{2}}=\sqrt{\frac{1}{N} \sum_{i=1}^{N}\left[\left(X_{c}-x_{i}\right)^{2}+\left(Y_{c}+y_{i}\right)^{2}\right]} \\
X_{c}=\sqrt{\frac{1}{N} \sum_{i=1}^{N} x_{i}, Y_{c}=\sqrt{\frac{1}{N} \sum_{i=1}^{N} y_{i}}}
\end{gathered}
$$

Determine the fractal dimension of the cluster by the formula

$$
D=\frac{\lg N}{\lg r_{d}-\lg r}
$$

Find the resistance of each cluster as the sum of the constriction resistances of the sliding contact upper and lower half-spaces, the resistance of the oxide film and the wear products $R_{c l i}=R_{C i}{ }^{\prime}+R_{C i}{ }^{\prime \prime}+R_{f i}+R_{w i}$, where:

$$
R_{c i}^{\prime}=\frac{\rho E^{\prime}}{4 D r_{d i}}, R_{c i}^{\prime \prime}=\frac{\rho E^{\prime \prime}}{4 D r_{d i}} .
$$

Calculate the contact resistance as a parallel connection of all clusters:

$$
\mathrm{R}=\left(\sum \mathrm{R}_{\mathrm{cli}}{ }^{-1}\right)^{-1}
$$

Calculate the full contact current $\left(R_{b r}\right.$ is the resistance of the brush body)

$$
I=\frac{U}{R_{b r}+R}
$$

Find the thermal power emitting in each cluster. Power contains electrical and mechanical components.

Electrical component:

$$
\begin{aligned}
& P_{E i}= \frac{\Delta U^{2}}{2 R_{d i}} \\
& \Delta U=U-I R_{b r}
\end{aligned}
$$

where $\Delta U$ is the voltage drop at the transient layer; $U$ is the voltage applied to the contact pair; $I$ is the current of $\mathrm{SC} ; R_{b r}$ is the brush resistance.

Mechanical power of friction:

$$
P_{M i}=S_{C i}+\Delta Y_{i} k_{f r} v,
$$

where $S_{C}$ is the CE stiffness, $\mathrm{N} / \mathrm{m} ; \Delta Y$ is the compression of $\mathrm{CE}, \mathrm{m} ; k_{f r}$ is the friction coefficient; $\mathrm{v}$ is the velocity of microreliefs displacement, $\mathrm{m} / \mathrm{s}$.

Then the total power in CE is

$$
P_{C E i}=P_{E i}+P_{M i}
$$

Determine the CE temperature increment for one step of modelling time. Since the emitting power is went into heating the $\mathrm{CE}$ volume to a temperature $\theta$ over a time $\Delta t$, then using the electrothermal analogy method [11] - [15] an equivalent electrical circuit can be made. The heat source of power $P_{C E}$ will be represented as the current source $I_{E}$ and the heat capacity of $\mathrm{CE} C_{C E}$ as the electrical capacitance $C_{E}$, and the voltage $U_{E}$ corresponds to the temperature $\theta$ (Fig. 1).Write in the operator form:

$$
\begin{gathered}
U_{E}(p)=I_{E} X_{C}(p)=\frac{I_{E}}{p C_{E}} \\
X_{C}=\frac{1}{p C_{E}} \quad \text { is the reactanct }
\end{gathered}
$$

where $\quad p C_{E}$ is the reactance of the capacitor $C_{E}$.

In accordance with the direct analogy:

$$
\theta(p)=\frac{P_{C E}}{p C_{C E}}, C_{C E}=C_{C E} m_{C E},
$$

where $c_{C E}$ is the specific heat; $m_{C E}=\Delta x^{2} \Delta h \rho_{C E}$ is the mass of CE; $\Delta h$ is the $\mathrm{CE}$ height; $\rho_{C E}$ is the average density of the CE materials

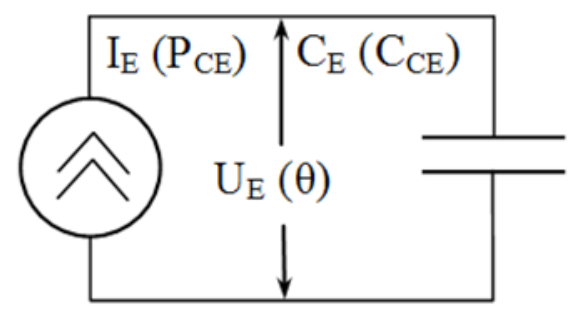

Fig. 1. Equivalent circuit.

$$
\begin{aligned}
& { }^{\text {After }}{ }^{\mathrm{r}} \theta(t)=\frac{P_{C E}}{C_{C E} \Delta x^{2} \Delta h \rho_{C E}} t^{\text {:get: }} \\
& { }_{\text {Repre: }} \Delta \theta=\frac{P_{C E}}{C_{C E} \Delta x^{2} \Delta h \rho_{C E}} \Delta t^{\text {rences: }}
\end{aligned}
$$

By the one step of the simulation the CE temperature will be:

$$
\theta_{i+1}=\theta_{i}+\Delta \theta
$$

The temperature of the $\mathrm{CE}$ has been changed due to heat exchange with the contacting bodies and the neighbour CE. Therefore, after calculating the temperature increment caused by heat emitting in $\mathrm{CE}$, we calculate the temperature distribution in the three-dimensional system of nodes over the same time interval (Fig. 2) using the explicit method [12], [13]. 
Taking into account the nonuniform distribution of thermal conductivity and heat capacity in the structure of the transition layer, we can write:

$$
\theta_{i, j, s}(t+\Delta t)=\left\{\begin{array}{l}
\theta_{i, j, s}(t)+ \\
F_{i+1, j, s}(t) \Delta \theta_{i+1, j, s}(t)+ \\
F_{i-1, j, s}(t) \Delta \theta_{i-1, j, s}(t) \\
F_{i, j-1, s}(t) \Delta \theta_{i, j-1, s}(t)+ \\
F_{i, j+1, s}(t) \Delta \theta_{i, j+1 s}(t)+ \\
F_{i, j, s+1}(t) \Delta \theta_{i, j, s+1}(t)+ \\
F_{i, j, s-1}(t) \Delta \theta_{i, j, s-1}(t)
\end{array}\right\},
$$

where $\theta_{i, j, s}(t)$ is the temperature of the node with coordinates $i, j, s ; \Delta \theta_{i+1, j, s}(t)=\theta_{i+1, j, s}(t)-\theta_{i, j, s}(t), \Delta \theta_{i-1, j, s}(t)$ $=\theta_{i-1, j, s}(t)-\theta_{i, j, s}(t)$, and etc. are the temperature differences of the calculated node

and the neighbor nodes; $\left.F_{i, j, x}=\frac{\left\langle k_{i, j}\right\rangle}{\left\langle c_{i, j}\right\rangle \Delta x^{2}\left\langle\rho_{i, j}\right\rangle}\right\rangle^{\Delta t}$ is Fourier number for the calculated node, where $\left(k_{i, j, s},\left(c_{i, j, s},\left(\rho_{i, j, s}\right)\right.\right.$ , are the average values of thermal conductivity, specific heat and density calculated by the nodes of the fragment (Fig. 2).

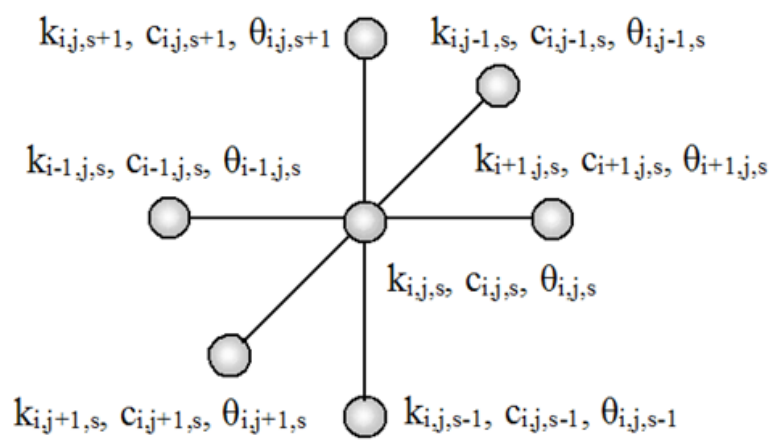

Fig. 2. Calculation of the sliding contact non-stationary temperature field.

The computational procedure has a stable solution if the Fourier number is less or equal 1/6 [12]. This indicator has the greatest value for the zones of direct conduction, therefore the choice of the step $\Delta t$ and the discretization $\Delta x$ are made by $\mathrm{CE}$ allocated into the specified zones.

The temperature increment of the $\mathrm{CE}$ from electromechanical heat emitting and its change due to the distribution of heat over the three-dimensional grid is not combined into a general procedure, since in this case the principle of simultaneous heat emitting in $\mathrm{CE}$ is violated. The calculation of the non-stationary temperature field of the SC is carried out for each $\Delta t$ in two steps and for analysis we use only the final values of the $\mathrm{CE}$ temperatures for the second step.

To simplify the algorithm and increase the speed, we introduce the assumption that the temperature of the $\mathrm{CE}$ layers adjacent to the contact is defined as the half sum of the average temperature of all calculated CE of the transient layer and the temperatures of the contacting bodies. We also neglect the convective heat transfer at the boundaries of the contact layer setting zero values of the thermal conductivity of boundary $\mathrm{CE}$ to the environment.

At each step of calculating the temperature field for all $\mathrm{CE}$, we check the condition for exceeding the critical temperature levels of materials: 1) the recrystallization temperature, 2) melting point, 3) the evaporation temperature. Depending on which interval the temperature of the calculated CE falls within, it is decided how to change its characteristics and parameters.

Up to the temperature $\theta$ m the mechanical stiffness of the $\mathrm{CE}$ is considered constant. In the interval $\theta \in\left[\theta_{\mathrm{m}}, \theta_{\mathrm{ev}}[\right.$, the stiffness of the $\mathrm{CE}$ is changing in linear dependence. When the temperature $\theta_{e v}$ is reached evaporation of the least heat-resistant material of the $\mathrm{CE}$ occurs and the distance between the contacting surfaces at this point increases. For this a correction is made in the matrix of micro-reliefs. The approach in $\mathrm{CE}$ is changed by the value of $\Delta h$. As a result at a constant pressing force $F_{n}$ the equivalent stiffness of the SC Скэ changes and the approach of the contacting surfaces is:

$$
\Delta Y=\frac{F_{b}}{S_{C E}}
$$

where $\mathrm{S}_{\mathrm{CE}}=\sum \mathrm{S}_{\mathrm{Ci}}$.

As the temperature increases the conductivity of the surface films also increases and when the certain temperature $\theta=\theta_{t b}$ is reached thermal breakdown occurs, which is defined as the transition of the $\mathrm{CE}$ to the direct conductivity state.

The fritting of oxide films is interpreted as the transition of the $\mathrm{CE}$ into the direct conduction state when the electric field strength reaches the threshold value $E_{f}$ that depends on the voltage at the contact layer and the thickness of the or $E=\frac{\Delta U}{d}$.

If $E>E_{f} C E$ goes into the direct conduction state.

The temperature dependence of the specific resistance, specific heat capacity, thermal conductivity and friction power is taken into account using

$$
\begin{gathered}
\rho_{\mathrm{E}}=\rho_{\mathrm{E} 0}(1+\alpha \Delta \mathrm{T}), \\
\mathrm{c}=\mathrm{c}_{0}\left(1+\alpha_{\mathrm{c}} \Delta \mathrm{T}\right), \\
P_{M}(T)=P_{M 0}\left(1-\left(\frac{\Delta T}{T_{*}-T_{0}}\right)^{2}\right),
\end{gathered}
$$

where $\rho_{E 0}$ is the electrical resistivity at the initial temperature; $\alpha$ is the temperature coefficient of resistance, $1 / K ; \Delta T$ is the difference between the current and initial temperatures; $c_{0}$ and $k_{0}$ are specific heat and thermal conductivity at the initial temperature; $\alpha_{c}$ and $\alpha_{k}$ are the temperature coefficients of specific heat and thermal conductivity; coefficient $\alpha_{k}$ may be, both positive and negative, depending on the materials of the SC; $P_{M 0}$ is the 
friction power at the initial temperature; $T$ is the current temperature; $\mathrm{n}$ and $T_{*}$ are the parameters which selected from the condition of the best approximation of the empirical dependence $P_{M}(T)$ in the studying temperature range.

The block diagram Fig. 3 depicts the main procedures of the simulation program. The main loop contains the block "Service input-output operations", which is responsible for the graphical interfaces of the program, the visualization of tables, graphs and color portraits, etc.

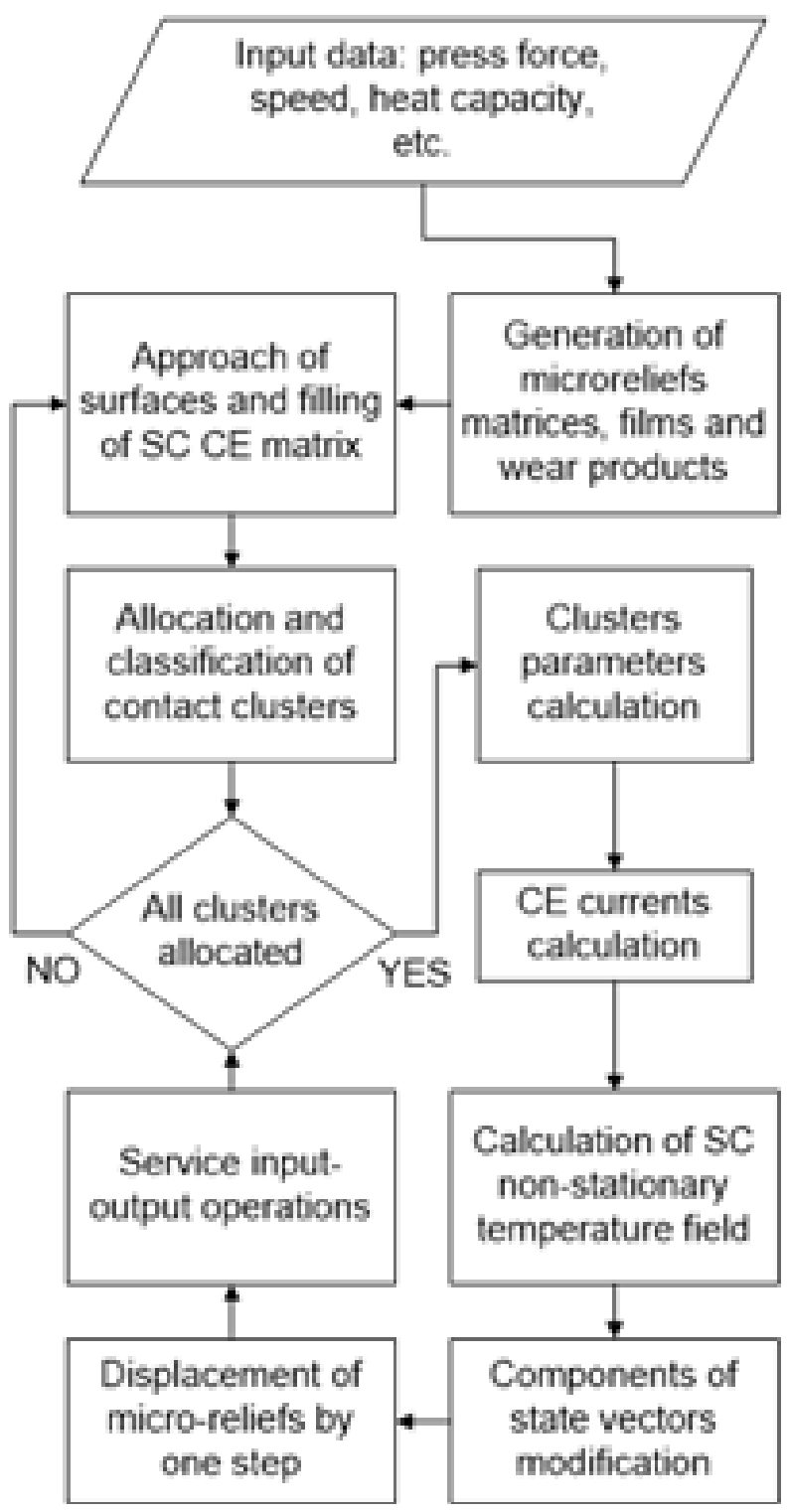

Fig. 3. Generalized block diagram of the EFI simulation model.

\section{Theoretical and Experimantal Study Of EFI DyNAMIC PROCESSES}

Objectives of the study are: 1) determination of the simulation model adequacy, 2) study of the qualitative regularities of the EFI dynamics related to the processes of formation and growth of conducting clusters in the transition layer, thermal processes and voltage-current dependencies generated by various disturbing influences. Similar studies are described in [16] - [22].

Let's compare some model and experimental characteristics.

The calculated voltage-current attractor shown in Fig. 4 is obtained with a sinusoidal modulation of the pressing force in the range from 2 to $25 \mathrm{~N}$ at the applied voltage $2 \mathrm{~V}$ and the speed of $3000 \mathrm{rpm}$ for the contact pair "brush-steel ring". Under the same conditions the experimental voltage-current limit cycle is shown in Fig. 5. The main difference is that the modulation of the pressing force in the experiment occurred naturally as the result of the interaction of the brush with the irregularities of the contact surface. In addition there was an effect of screw thread of the steel ring on the contact area value. The randomness of the phase trajectory shown in Fig. 5 is explained by the result of the action of these two polyharmonic factors. Despite all its complexity the indicated trajectory was steadily reproduced on each revolution of the ring with the slight stochastic variations.

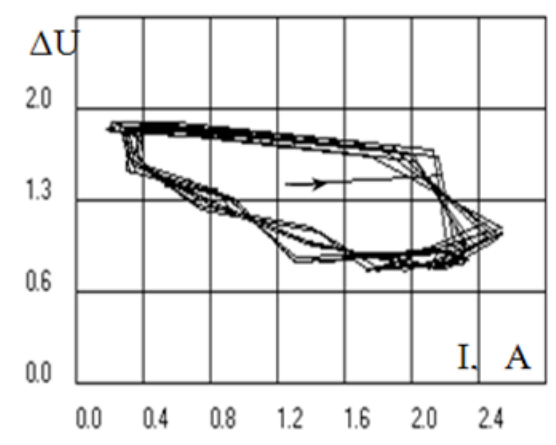

Fig. 4. Calculated voltage-current attractor.

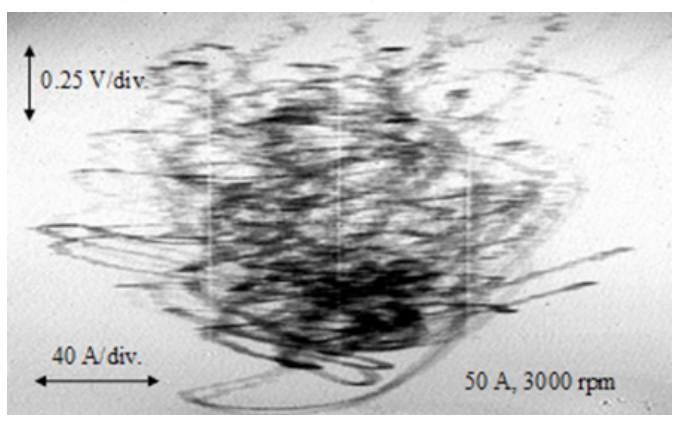

Fig. 5. Experimental voltage-current attractor.

Statistical estimates of these curves is the ranges of current $I$ and voltage drop $\Delta U$ are almost match. For $I_{\text {exp }}$ the range of variation is about $200 \mathrm{~A}$ and for $I_{\text {calc }}$ the range is calculated as $2.3 \cdot 89=204.3 \mathrm{~V}$. For $\Delta U_{\text {exp }}$ and $\Delta U_{\text {calc }}$ the ranges are quite close.

In the Fig. 6 the model dynamic voltage-current characteristic obtained by high-frequency sinusoidal modulation of the applied voltage is shown.

For comparison to the model the experiment was performed on the collector. Initial data: speed $1000 \mathrm{rpm}$, press force $20 \mathrm{~N}$, voltage $4 \mathrm{~V}$. Fig. 6 corresponds to the experimental oscillogram in Fig. 7. 


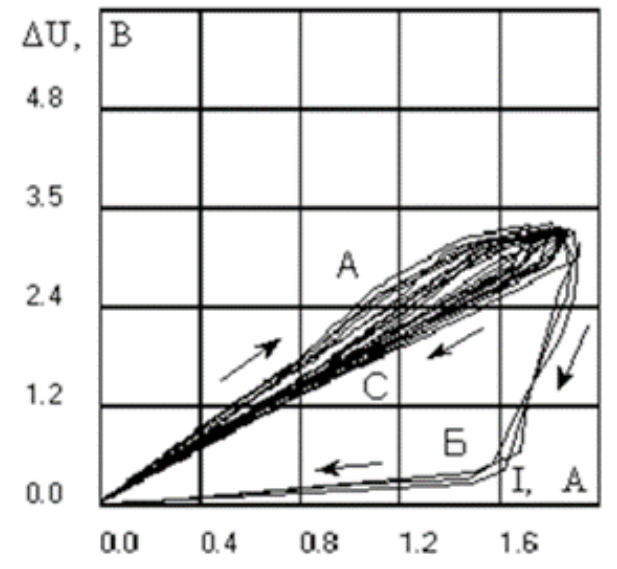

Fig. 6. Theoretical voltage-current attractor.

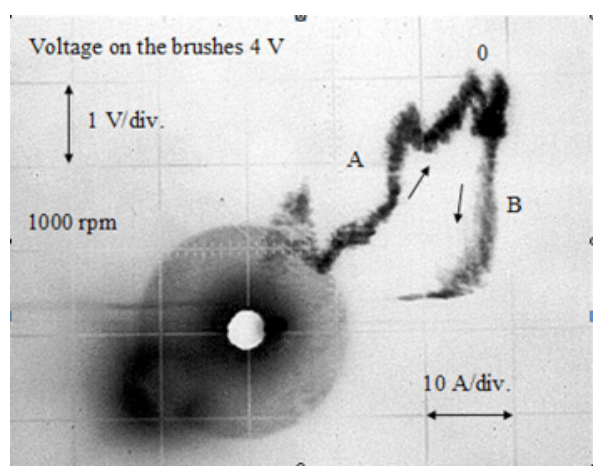

Fig. 7. The voltage-current attractor recorded during the passage of the collector lamella under the brush.

The simulation program allows to observe movement and development of the interacting microreliefs, aggregation of conducting clusters in the contact transition layer and the non-stationary temperature field. Fig. 8 shows examples of images obtained in the modelling process.
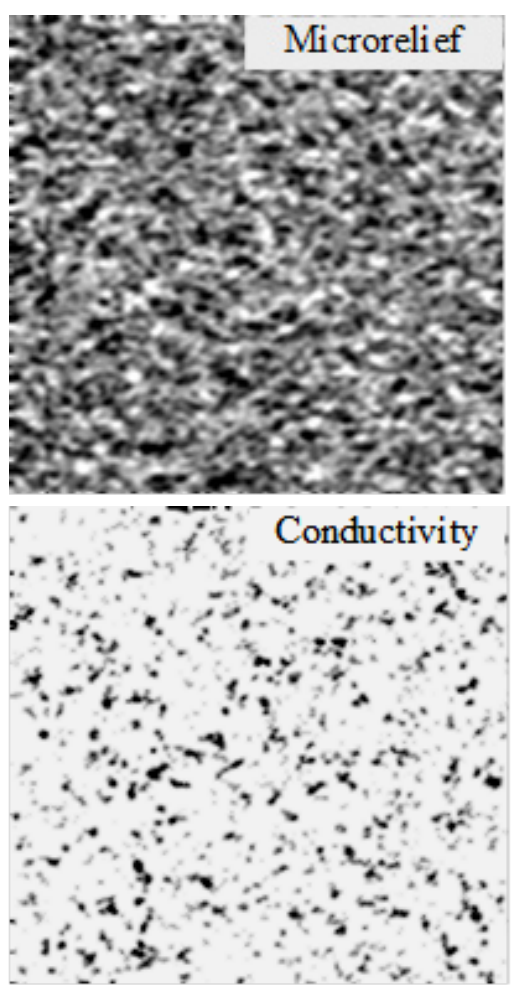

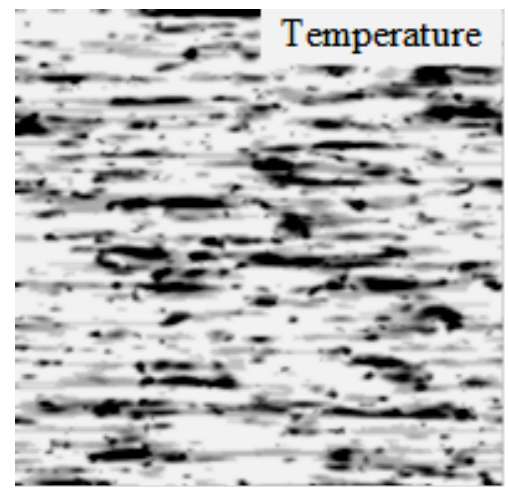

Fig. 8. Typical simulation images of the EFI synergistic model.

Fig. 9 shows enlarged fragments of the conduction in the contact transition layer, which contain characteristic conducting clusters. The shade portraits of the thermal field corresponding to the areas of conductivity show the values of local temperatures in various contact zones.
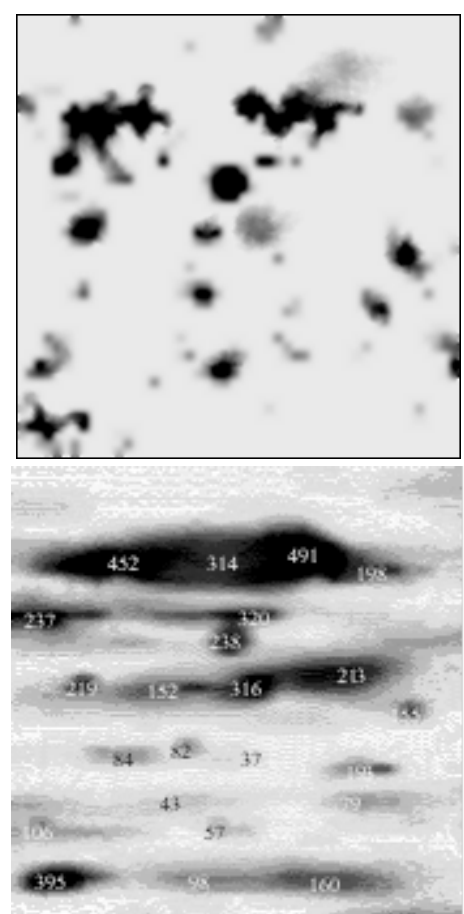

Fig. 9. Enlarged fragments of the conductivity containing characteristic contact clusters, and temperature field with indication of local temperatures (press force $30 \mathrm{~N}$, voltage $2.5 \mathrm{~V}$, velocity $30 \mathrm{~m} / \mathrm{s}$, contact is "brush EG-4 - steel").

Many conducting clusters have an oval or circular configuration. Usually they are located in less saturated areas with a relatively low average temperature. In the areas of increased heating a significant part of the clusters has a larger size and a complex configuration characterized by fractional fractal dimension. In addition, thermal zones are strongly elongated by the axis of the contact surface motion.

\section{CONCLUSIONS}

The structure of conductivity and thermal field is significantly influenced by the value of thermal conductivity of contact pair materials.

At low thermal conductivity the heated zones are elongated by the axis of contacting bodies movement and 
take the form of diffuse strips.

With high thermal conductivity thermal zones acquire the local forms and at the same time have a lower temperature.

When certain values of the voltage and the press force are reached the temperature of a large number of thermal clusters reaches values at which the melting of the lowermelting material of the contact pair occurs. In practice, such modes of operation should be accompanied by increased sparking caused by the spitting of molten metal particles from the contact zone.

Most conductive clusters located in areas with low average temperature are oval or round in shape.

Clusters located in zones with a high average temperature have a larger size and a complex configuration characterized by fractional fractal dimension.

With an increase in the press force () the current, the saturation of the contact layer with conducting clusters, the number and temperature of the heated spots quickly increase.

Increasing the voltage at increases the density of conductive clusters at a lesser degree, however it affects the temperature field almost the same way as press force.

\section{REFERENCES}

[1] G. Haken, Sinergetika. M.: Mir, 1980.

[2] I. M. Yaglom, Sovremennaya kulytura I kompyutery. M.: Nauka, 1990.

[3] B. R. Fuller, Sinergetics. N.Y.: MacMillan, 1982.

[4] G. Haken Informatsiya i samoorganizatsiya. Makroskopicheskiy podhod k slozhnym sistemam. M.: Mir, 1991.

[5] S. V. Emelyanov, V. I. Utkin V. A. Taran i dr., Teoriya sistem s peremennoy strukturoy. M.: Nauka, 1970.

[6] Г. П. Гладышев, Термодинамика и макрокинетика природных иерархических процессов. М.: Наука, 1988.

[7] B. B. Mandelbrot, The fractal geometry nature. N.Y.: Freeman, 1983.

[8] E. Feder, Fraktaly. M.: Mir, 1991.

[9] B. M. Smirnov, Fizika fraktalynyx klasterov. M.: Nauka, 1991

[10] Fraktaly v fizike, Trudy VI mezhdunarodnogo simpoziuma po fraktalam v fizike. M.: Mir, 1988.

[11] V. P. Isachenko, V. A. Osipova, A. S. Sukomel, Teploperedacha. M.: Energoizdat, 1981.
[12] F. Kreit, U. Blek, Osnovy teploperedachi. M.: Mir, 1983.

[13] I. M. Tetelybaum, Ya. I. Tetelynaum, Modeli pryamoi analogii. M.: Nauka, 1979.

[14] I. M. Tetelybaum, Yu. R. Shneider, Praktika analogovogo modelirovaniya dinamicheskih sistem. M.: Energoatomizdat, 1987.

[15] V. A. Venikov, G. V. Venikov, Teoriya podobiya i modelirovaniya (primenitelyno k zadacham elektroenergetiki). M.: Vysshaya shkola, 1984.

[16] A. Ilyin, I. Plokhov, I. Savraev, O. Kozyreva, N. Kotkov, "Forming and overlapping microreliefs in sliding contact simulation model,“ in Environment. Technology. Resources: Proceedings of the 11th International Scientific and Practical Conference, Volume III, Rezekne: Latvia, 2017, pp. 102-106, http://dx.doi. org/10.17770/etr2017vol3.2532

[17] I. Plokhov, I. Savraev, A. Markov, A. Ilyin, O. Kozyreva, N. Kotkov, "Industrial tests of current distribution dynamics in the brush-contact apparatus of the turbo-generator," in Environment. Technology. Resources, Rezekne, Latvia, Proceedings of the 11th International Scientific and Practical Conference, Volume III, Rezekne: Latvia, 2017, pp. 258-268, http://dx.doi.org/10.17770/ etr2017vol3.2661

[18] O. Kozyreva, I. Plokhov, N. Kotkov, I. Savraev, A. Ilyin, "Experimental investigations of effect of LC-circuits on sparking and thermal state of sliding electric contact unit," in Environment. Technology. Resources, Rezekne, Latvia, Proceedings of the 11th International Scientific and Practical Conference, Volume III, Rezekne: Latvia, 2017. pp. 150-153, http://dx.doi.org/10.17770/ etr2017vol3.2575

[19] O. Kozyreva, I. Plokhov, I. Savraev, A. Ilyin, "Reducing sparking in the transient layer of the sliding electrical contact unit," in 2018 19th International Scientific Conference on Electric Power Engineering (EPE), 16-18 May 2018, Brno, Czech Republic, 2018, pp. 189-193, https://doi.org/10.1109/EPE.2018.8395969

[20] O. Kozyreva, Y. Guravlev, I. Plokhov, I. Savraev, A. Ilyin, "The regions of parametric instability of brush-contact device electromagnetic circuit in unstable working conditions," in Environment. Technology. Resources. Proceedings of the 10th International Scientific and Practical Conference, Volume 1, Rezekne, Latvia, 2015, pp. 84-88, http://dx.doi.org/10.17770/etr2015vol1.218

[21] A. Ilyin, I. Plokhov, I. Savraev, O. Kozyreva, "Modeling of time dependent thermal process in sliding electrical microcontact," in Environment. Technology. Resources. Proceedings of the 10th International Scientific and Practical Conference, Volume 3, Rezekne, Latvia, 2015, pp. 109-113, http://dx.doi.org/10.17770/ etr2015vol3.194

[22] I. Plokhov, A. Ilyin, O. Kozyreva, I. Savraev, "The simulation model of sliding contact with three degrees of freedom and distributed parameters of the transition layer," in Environment. Technology. Resources. Proceedings of the 10th International Scientific and Practical Conference, Volume 3, Rezekne, Latvia, 2015, pp. 182-186, http://dx.doi.org/10.17770/etr2015vol1.229 